\title{
Hubungan Frekuensi Menguras Terhadap Pertumbuhan Jamur Pada Air Bak Toilet Tempat Wisata Di Wilayah Kota Kediri
}

\author{
Durroh Humairoh ${ }^{1}$, Endrik Asmarani \\ ${ }^{1)}$ Institut Ilmu Kesehatan Bhakti Wiyata Kediri, Kediri, Indonesia \\ ${ }^{1)}$ durrohhumairoh@gmail.com
}

Tanggal Submit: 28 Januari 2019

Tanggal Review: 03 Mei 2019

Tanggal Publish

Online:

19 Juli 2019

\begin{abstract}
Tourist attractions are an interesting place to go with colleagues, friends, or family for a vacation. Every tourist spot is always equipped with clean toilets for the convenience of visitors. In tourist attractions that provide public toilets, they must always be cleaned regularly so they are not infected by microorganisms that can endanger health. In this study, research was conducted on several tourist toilets in the city of Kediri. The method used in this study was centrifugation of 15 tourist attractions in the city of Kediri. The results of the study using the spearmans rho correlation test showed that there was a correlation between the frequency of drainage with mold growth in toilet water and the results showed that the longer the frequency of drainage of the toilet, the higher the number of fungus in the toilet water.
\end{abstract}

Keywords: drain frequency, number of fungus, tourist attractions

\section{PENDAHULUAN}

Tempat wisata merupakan salah satu tempat umum yang menyediakan fasilitas toilet umum. Toilet umum pada tempat wisata merupakan sarana sanitasi bagi wisatawan dari berbagai kalangan masyarakat dengan latar belakang hygiene dan sanitasi yang beragam (Bagiastra, 2013) Sesuai dengan Undang-Undang Kepariwisataan (2009) tujuan wisata atau destinasi wisata merupakan kawasan geografis yang berada di dalam satu wilayah administratif di dalamnya terdapat daya tarik wisata, fasilitas umum, fasilitas wisata, aksibilitas serta masyarakat yang saling berkaitan dan melengkapi terwujudnya kepariwisataan. Dengan daya tarik tertentu tempat wisata menjadi salah satu alasan orang untuk berkunjung ke suatu tempat di salah satu kota, daerah atau bahkan Negara. Oleh sebab itu toilet umum pada tempat wisata perlu diperhatikan hygiene sanitasinya agar tidak menjadi penyebab penularan penyakit serta dapat meningkatkan citra sebuah bangsa (Adiwoso, 2016).

Toilet merupakan sarana sanitasi yang penting bagi manusia. Toilet 
umum dirancang lengkap dengan kloset, air dan perlengakapan pendukung lain yang bersih, aman dan higienis sehingga masyarakat yang berada pada tempattempat umum dapat membuang hajat, serta memenuhi kebutuhan fisik, sosial dan psikologis lainnya. Fungsi toilet umum yang diperuntukkan sebagai sarana sanitasi bagi pengunjung yang mengujungi suatu tempat tertentu menyebabkan toilet umum digunakan secara bergantian dan penggunanya beragam. Sebagai akibatnya, toilet umum merupakan sarana yang paling memungkinkan terjadinya penularan penyakit apabila kebersihannya tidak dijaga dengan baik (Bagiastra, 2013).

Kota Kediri merupakan wilayah di Jawa Timur yang merupakan kota terbesar ketiga setelah Surabaya dan Malang menurut jumlah penduduknya. Kota Kediri memiliki berbagai tempat wisata yang sarat akan nilai sejarah, budaya dan keindahan alamnya. Kota Kediri memiliki destinasi wisata diantaranya Goa Selomangleng, Museum Airlangga, Taman Sekartaji, wisata kolam renang Pagora dan lain sebagainya. Dengan banyaknya pilihan destinasi wisata di kota Kediri semakin banyak di kunjungi wisatawan local maupun mancanegara (Bapenas Kota Kediri, 2013). Sebaian besar bahkan hampir di setiap tempat wisata di Kota Kediri masih meyediakan fasilitas toilet umum dengan air yang ditampung di dalam bak toilet berupa bejana atau ember plastik daripada toilet dengan kloset yang di lengkapi dengan shower jet. Pengurasan atau pergantian air bak toilet juga tidak dilakukan setiap hari oleh petugas kebersihan tempat wisata.

Kebersihan toilet dapat dijadikan ukuran terhadap kualitas manajemen sanitasi pada suatu tempat (Dwipayanti, 2008). Model toilet di Indonesia masih banyak yang menggunakan tempat penampungan air berupa bejana atau bak penampung (Adiwoso, 2016). Air yang ditampung pada bak toilet dapat tercemar berbagai bahan kontaminan salah satunya mikroorganisme berupa jamur. Jamur yang mengkontaminasi air, khususnya air bak toilet dapat menyebabkan penyakit pada organ genital (Parahatamaputra, 2009).

Kontaminasi air bak toilet dapat terjadi dari lingkungan sekitar toilet, perilaku pengguna dan sumber air yang digunakan. Lingkungan sekitar toilet turut berperan dalam pencemaran air bak toilet yaitu, kondisi sekitar toilet yang cukup lembab, kurang baiknya sistem saluran pembuangan air sehingga air menggenang di lantai toilet cukup lama, serta tidak tersedianya tempat sampah dapat mengakibatkan sampah yang dibuang pengguna toilet menjadi sumber penyebab jamur tumbuh. Perilaku pengguna toilet seperti mencuci tangan 
tanpa menggunakan sabun setelah defekasi dan setelah kontak dengan benda yang terpapar jamur (Qurrohman \& Nugroho, 2016).

Jamur atau fungi adalah organisme heterotrofik yang memerlukan senyawa organik untuk nutrisinya (Irianto, 2014). Semua jamur bersifat aerobik, yakni memerlukan oksigen untuk pertumbuhannya, namun kebanyakan jamur dapat tumbuh baik pada $\mathrm{pH}$ yang luas antara 2,8-8,5. Jamur bersifat psikotrofik dapat tumbuh pada suhu almari es, dan beberapa bahkan masih dapat tumbuh lambat di bawah suhu pembekuan, misalnya $-5^{\circ} \mathrm{C}$ sampai $-10^{\circ} \mathrm{C}$. Selain itu ada jamur bersifat termofilik yang mampu tumbuh pada suhu tinggi (Waluyo, 2016).

Parameter kebersihan toilet salah satunya adalah frekuensi menguras bak toilet atau pergantian air bak toilet. Pengurasan bak toilet dapat dilakukan dengan pembersihan menggunakan cairan pembersih dan penambahan desinfektan. Kurangnya frekuensi menguras air bak toilet umum memberikan kesempatan jamur untuk tumbuh dalam air sehingga menyebabkan penyakit bagi penggunanya (Prahatamaputra, 2009). Dengan demikian, perlu dilakukan penelitian mengenai adanya pertumbuhan jamur pada air bak toilet terkait frekuensi menguras air bak toilet umum di tempat wisata. Tujuan penelitian ini adalah untuk mengetahui hubungan frekuensi menguras air bak toilet terhadap pertumbuhan jamur pada toilet tempat wisata di Kota Kediri.

\section{METODE PENELITIAN}

Lokasi pengambilan sampel dilakukan di beberapa toilet yang dilengkapi dengan bak penampung air pada beberapa tempat wisata di Kota Kediri. Lokasi penelitian dilaksanakan di Laboratorium Mikologi Institut Ilmu Kesehatan Bhakti Wiyata Kediri. Waktu penelitian dilaksanakan pada bulan Juli 2018.

Penelitian ini merupakan jenis penelitian deskriptif kuantitatif dengan sampel yang diperiksa sebanyak 45 air bak toilet tempat wisata di Kota Kediri. Teknik sampling menggunakan random sampling. Dalam penelitian ini pengambilan sampel didasarkan pada toilet tempat wisata di Kota Kediri dengan memilih toilet dengan bak penampung air. Pengambilan air bak toilet dilakukan pada sore hari.

Alat yang digunakan dalam penelitian ini meliputi spuit $10 \mathrm{cc}$, ice box, cooling box, tabung centrifuge, rak tabung, centrifuge, mikroskop, erlenmeyer, beaker glass, plate, ose bulat dan jarum, objek glass, cover glass, plastik wrap, kapas dan lampu spiritus. Bahan penelitian adalah air bak 
toilet dan aquadest sebagai pelarut media serta control negatif. Media yang digunakan Saboraud Dextrosa Agar (SDA) dan cat yang digunakan Lactophenol Cotton Blue (LCB).

Prosedur penelitian tahap pertama adalah pra analitik meliputi persiapan pengambilan sampel dan pengambilan sampel air bak toilet sebagai berikut: Sampel pada bak penampung air homogenkan dengan cara diaduk, lalu sampel kemudian diambil menggunakan spuit 10cc melewati pangkal jarum yang segera ditutup kembali setelah badan spuit terisi sampel, Kemudian sampel yang tidak segera diperiksa dalam waktu 2 jam segera di masukkan pada ice box berisi cooling box.

Tahap selanjutnya adalah analitik (Perlakuan sampel metode centrifugasi) meliputi: Disiapkan tabung centrifuge steril bertutup, rak tabung dan lampu spirtus, lalu dimasukkan sampel pada tabung centrifuge secara aseptic didekatkan lampu spirtus kemudian ditutup kembali, lalu dicentrifuge selama 10 menit dengan kecepatan 1500 rpm, kemudian sampel air bagian atas dibuang hingga menyisakan 1cc bagian paling bawah. Kemudian sampel yang telah dicentrifuge dituang pada plate steril sebanyak $1 \mathrm{cc}$ secara aseptic didekatkan lampu spirtus. Ditambahkan media SDA ditunggu sampai memadat dan diinkubasi pada suhu kamar selama 72 jam.

Tahap berikutnya adalah identifikasi sampel secara makroskopis maupun mikroskopis. Secara makroskopis jamur diidentifikasi dengan memperhatikan ciri-ciri morfologi koloni yang tumbuh pada media SDA dengan ciri bentuk koloni jamur, tekstur kapas, serbuk, atau bludru dan konsistensi yang kering. Kemudian dilanjutkan identifikasi sampel secara mikroskopis. Yakni dipanaskan ose bulat sampai membara kemudian didinginkan. Lalu disiapkan cat Lactophenol Cotton Blue (LCB) pada objek glass. Kemudian koloni diambil menggunakan ose bulat kemudian dicampur dengan cat LBC dan ditutup dengan cover glass. Kemudian diamati dibawah mikroskop perbesaran 10x untuk mencari lapang pandang dan diubah perbesaran 40x untuk memperjelas bentuk jamur.

Tahap akhir adalah post analitik meliputi pelaporan hasil makroskopis yakni adanya jamur dalam air bak toilet pada tempat wisata di Kota Kediri. Pelaporan hasil secara makroskopis didasarkan pada bentuk koloni jamur yang tumbuh pada media Saboraud Dextrosa Agar (SDA) meliputi bentuk, warna, tekstur dan konsistensi koloni. Serta pelaporan hasil mikroskopis yakni adanya jamur dengan pengecatan 
menggunakan LCB. Pelaporan hasil meliputi adanya hifa, miselium dan spora dengan ciri-ciri sesuai jamur yang dimaksud.

\section{Analisis Data}

Tahap analisis dilakukan dengan uji korelasi antara frekuensi lama menguras air bak toilet dengan jumlah jamur yang tumbuh saat pemeriksaan air tersebut pada media. Sebelum uji korelasi dilakukan uji normalitas menggunakan Kolmogorov-smirnov, karena hasil menunjukkan tidak normal dengan niali signifikansi kurang dari $0,05(0,01)$ untuk frekuensi menguras dan $(0,001)$ untuk jumlah jamur sehingga uji korelasi menggunakan spearman-rho, dan hasil menunjukkan nilai signifikansi 0,00 yang berarti terdapat hubungan antara frekuensi menguras dengan jumlah jamur pada air bak toilet di tempat wisata wilayah kota Kediri.

\section{HASIL}

Hasil eksplorasi jumlah jamur yang tumbuh pada air bak toilet di tempat wisata wilayah Kota Kediri dapat dilihat pada Tabel 1 berikut.
Tabel 1. Jumlah Jamur yang Tumbuh Pada Air Bak Toilet di Tempat Wisata Wilayah Kota Kediri

\begin{tabular}{|c|c|c|c|c|}
\hline NO & $\begin{array}{l}\text { Tempat } \\
\text { Wisata }\end{array}$ & $\begin{array}{c}\text { Frekuensi } \\
\text { Menguras } \\
\text { (Hari/sekali } \\
\text { kuras) }\end{array}$ & $\begin{array}{l}\text { Jenis } \\
\text { Jamur }\end{array}$ & $\begin{array}{l}\text { Jenis } \\
\text { Jamur }\end{array}$ \\
\hline 1. & Wisata A & 2 & 1 & $\begin{array}{c}\text { Rhizopus } \\
\text { sp. }\end{array}$ \\
\hline 2. & Wisata B & 3 & 3 & $\begin{array}{c}\text { Mucor sp., } \\
\text { Rhizopus } \\
\text { sp., } \\
\text { Aspergillus } \\
\text { fumigatus }\end{array}$ \\
\hline 3. & Wisata C & 1 & 0 & - \\
\hline 4. & Wisata D & 3 & 3 & $\begin{array}{c}\text { Mucor sp., } \\
\text { Rhizopus } \\
\text { sp., } \\
\text { Aspergillus } \\
\text { fumigatus }\end{array}$ \\
\hline 5. & Wisata E & 1 & 0 & - \\
\hline 6. & Wisata F & 1 & 0 & - \\
\hline 7. & Wisata $\mathrm{G}$ & 3 & 3 & $\begin{array}{c}\text { Mucor sp., } \\
\text { Rhizopus } \\
\text { sp., } \\
\text { Aspergillus } \\
\text { fumigatus }\end{array}$ \\
\hline 8. & Wisata $\mathrm{H}$ & 1 & 0 & - \\
\hline 9. & Wisata I & 1 & 0 & - \\
\hline 10. & Wisata J & 2 & 0 & - \\
\hline 11. & Wisata $\mathrm{K}$ & 2 & 0 & - \\
\hline 12. & Wisata L & 1 & 0 & - \\
\hline 13. & $\begin{array}{c}\text { Wisata } \\
\text { M }\end{array}$ & 3 & 2 & $\begin{array}{c}\text { Rhizopus } \\
\text { sp., } \\
\text { Candida } \\
\text { sp. }\end{array}$ \\
\hline 14. & Wisata N & 2 & 1 & $\begin{array}{c}\text { Rhizopus } \\
\text { sp. }\end{array}$ \\
\hline 15. & Wisata O & 3 & 2 & $\begin{array}{c}\text { Rhizopus } \\
\text { sp., } \\
\text { Candida } \\
\text { sp. }\end{array}$ \\
\hline
\end{tabular}

Dari Tabel 1 menunjukkan bahwa yang frekuensi mengurasnya lebih lama 3 hari sekali seperti tempat wisata $\mathrm{B}, \mathrm{D}$, $\mathrm{G}, \mathrm{M}$, dan $\mathrm{O}$ maka semakin banyak ditumbuhi oleh berbagai jamur kontaminan seperti Mucor sp., Aspergillus fumigatus, Rhizopus sp., dan Candida sp. Sedangkan yang dilakukan 
pengurasan 1-2 hari sekali didapatkan hanya 1 jamur saja yang mengontaminasi.

\section{PEMBAHASAN}

Pada hasil tersebut menunjukkan bahwa frekuensi menguras air bak toilet dapat mempengaruhi tinginya kontaminasi jamur pada air bak toilet tersebut. Terlihat dari semakin lama hari masa untuk menguras, maka jamur yang mengontaminasi juga akan semakin banyak. Trend ini terlihat dari tempat wisata $\mathrm{B}, \mathrm{D}, \mathrm{G}, \mathrm{M}$, dan $\mathrm{O}$ yang samasama melakukan pengurasan bak toiletnya 3 hari sekali ditumbuhi oleh jenis jamur yang sama yakni Mucor sp., Rhizopus sp., Aspergillus fumigatus, Candida sp. seperti pada gambar makroskopis dan mikroskopis 1a, 1b, 2a, 2b, 3a, 3b, 4a dan 4b.

Hal ini sesuai dengan penelitian yang dilakukan oleh Qurrohman dkk. (2015) bahwa tingginya jumlah kontaminasi jamur Candida sp. pada air bak toilet erat kaitanya dengan frekuensi menguras air bak toilet tersebut, karena pada dasarnya pengurasan sangat berpengaruh dengan kebersihan serta kualitas dari air dalam bak penampungan dimana hal tersebut dapat meningkatkan kontaminasi dari Candida sp. Pengurasan dapat berfungsi untuk memperbaharui air sehingga dapat memperkecil kontaminasi mikroorganisme. Pernyataan tersebut semakin dikuatkan oleh Prahatamaputra (2009) yang menyebutkan bahwa penggunaan air yang mengalir lebih baik dari pada air yang diam ditampung dalam bak air, karena memiliki persentase lebih kecil untuk terkontaminasi oleh jamur, karena pada penelitian ini air yang diperiksa merupakan air yang ditampung di bakbak toilet pada tempat wisata yang tersebar di wilayah Kota Kediri. Berikut merupakan gambar pemeriksaan makroskopis dan mikroskopis jamur yang ditemukan saat eksplorasi jamur di berbagai tempat wisata di wilayah Kota Kediri. 

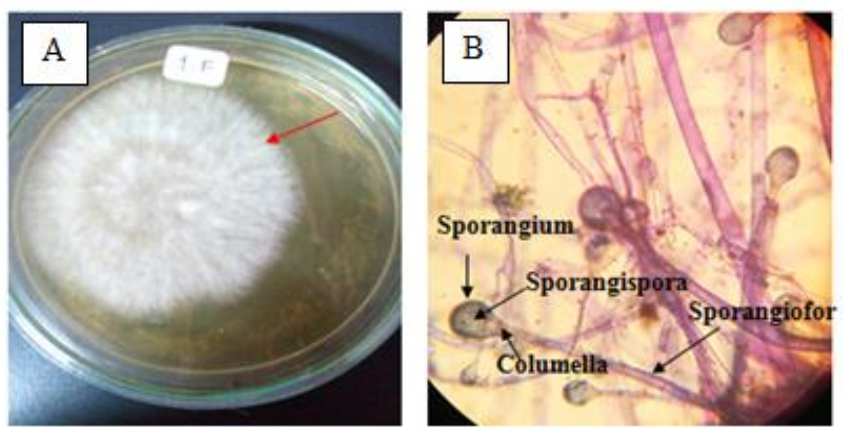

Gambar 1. A) Makroskopis Rhizopus sp., B) Mikroskopis Rhizopus sp.
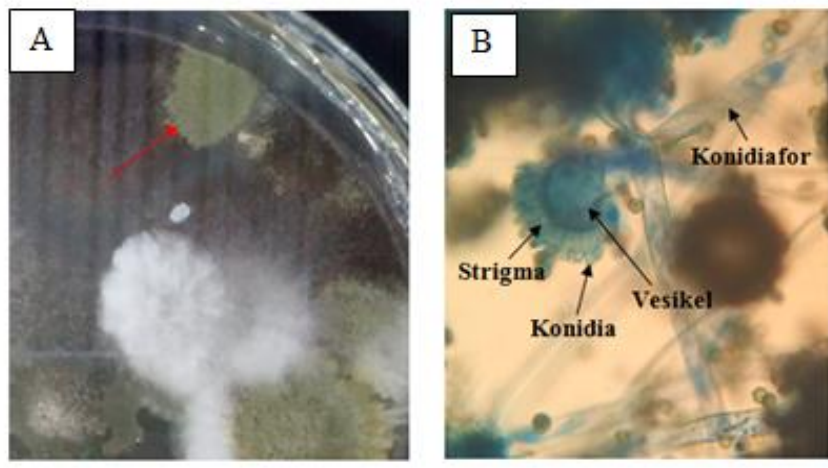

Gambar 2. A) Makroskopis Aspergillus fumigatus., B) Mikroskopis Aspergillus fumigatus
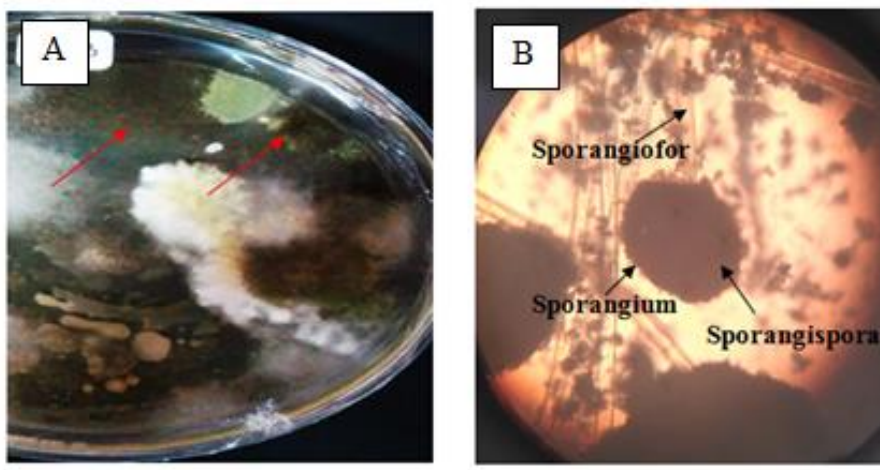

Gambar 3. A) Makroskopis Mucor sp., B) Mikroskopis Mucor sp.
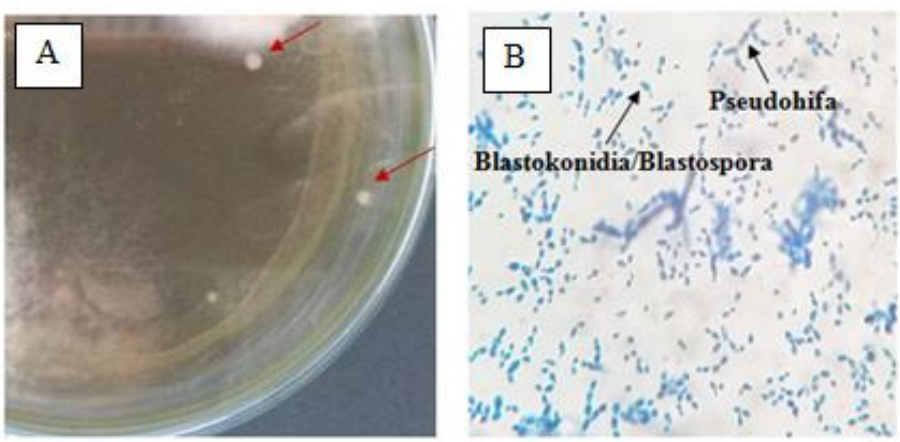

Gambar 4. A) Makroskopis Candida sp., B) Mikroskopis Candida sp. 
Selain beberapa faktor diatas, cara pembersihan bak pada setiap toilet juga mempengaruhi tingginya kontaminasi jamur yang ada. Penelitian Qurrohman (2015) menyebutkan bahwa beberapa SPBU di wilayah Surakarta memiliki metode menguras yang berbeda-beda. Beberapa SPBU ada yang menguras bak toilet hanya dengan menyikat saja tanpa dibersihkan dengan cairan pembersih, tetapi hasilnya jumlah kontaminasi jamur lebih besar daripada yang digosok dengan cairan pembersih. Sebenarnya, selain dari faktor metode pembersihan, kontaminasi yang terjadi pada air bak toilet juga bisa disebabkan oleh beberapa hal, antara lain kontaminasi yang berasal dari sumber air, kontaminasi dari para pengunjung, maupun beberapa faktor pendukung lain seperti kurangnya kesadaran pengunjung dalam menjaga kebersihan air dalam toilet.

Air toilet yang diperiksa merupakan air yang ditampung dalam bak penampungan sehingga kualitas kebersihannya tidak terjamin. Kualitas air sangat penting bagi kesehatan kita. Salah satu masalahnya adalah kontaminasi mikroorganisme patogen. Jamur dicatat sebagai penyebab signifikan pencemaran air karena memiliki kemampuan untuk bertahan hidup. Jamur telah dilaporkan sebagai polutan dan kontaminan dari semua jenis air (Yousefi, 2013).

Hasil uji Korelasi menggunakan Spearman-rho juga menunjukkan bahwa semakin lama frekuensi menguras, maka pertumbuhan jamur kontaminan juga akan semakin tinggi. Hal ini ditunjukkan dengan nilai signifikansi yang 0,00 $(\square<0,05)$. Sebelum tes korelasi dilakukan, harus di uji Kolmogorovsmirnov dulu untuk melihat normalitasnya, hasil menunjukkan bahwa data tidak normal dengan nilai sig. 0,010 untuk frekuensi menguras dan 0,001 untuk pertumbuhan jamur terlihat pada Tabel 2. Seluruh nilai signikansi uji normalitasnya $<0,05 \quad$ sehingga menunjukkan data tidak normal dan harus dilanjutkan pada uji nonparametrik uji korelasi Spearman-rho.

\section{SIMPULAN}

Berdasarkan hasil penelitian dan pembahasan dapat disimpulkan bahwa terdapat hubungan antara frekuensi menguras dengan pertumbuhan jamur pada air bak toilet di beberapa tempat wisata wilayah Kota Kediri. Semakin lama frekuensi menguras, maka semakin tinggi pertumbuhan jamur kontaminan pada air bak toilet tersebut. 
SARAN

Berdasarkan penelitian yang telah dilakukan, maka disarankan bagi para pengunjung tempat wisata untuk selalu memperhatikan kondisi airnya, kondisi bak toilet, serta lebih memilih menggunakan shower jet daripada air bak dalam tampungan. Bagi peneliti selanjutnya supaya melengkapi data dengan jumlah koloni masing-masing jamur kontaminan, serta menyertakan kontaminasi baik dari kelompok yeast.

\section{DAFTAR PUSTAKA}

Adiwoso, N. 2016. Pedoman Standart Toilet Umum Indonesia. Asosiasi Toilet Indonesia.

Bagiastra, I K. 2013. Analisis Manajemen Toilet Umum Di Kawasan Wisata Lombok. Media Bina Ilmiah. 7.(6): 10-15.

Dwipayanti, U. 2008. Ketersedian Pengelolaan Toilet Di Tempat Wisata Di Pulau Bali. Universitas Udayana.

Prahatamaputra, A. 2009. Karakteristik Jamur Candida Albicans Berbasis Fermentasi Karbohidrat Pada Air Bak WC Sekolah Menengah Di Kelurahan Alalak Utara. Jurnal WahanaBio . 2 : 1-13.

Qurrahman, M. T. \& Rosid W. N. 2015. Pengaruh Frekuensi Menguras Terhadap Jumlah Candida sp. Pada Air Bak Toilet di SPBU Surakarta. Jurnal Ilmiah Biologi Biogenesis. 3 (1). 23-27.

UU RI Kepariwisataan. 2009. Undang Undang Republik Indonesia Tentang Kepariwisataan. Jakarta : Sekertariat Negara RI.
Irianto, K. 2014. Bakteriologi Medis, Mikologi Medis, dan Virologi Medis (Medical Bacteriology, Medical Mycology, and Medical Virology. Bandung: Alfabeta.

Notoadmodjo, $\quad$ S. 2010. Metodologi Penelitian Kesehatan. Jakarta : PT. Rineka Cipta.

Waluyo, L. 2016. Mikrobiologi Umum Edisi Revisi. Malang : Penerbitan Universitas Muhmamadiyah Malang.

Yousefi, Z., Aghili, S.R., Ebrahimzadeh, R., \& Salmanian, B. 2013. Investigation of Fungi in Drinking Water Resources, as a Source of Contamination tap Water in Sari, Iran. Iranian journal of health sciences, vol. $1(1), 84-91$. 